\title{
Muscle cramps: A 'complication' of cirrhosis
}

\author{
Paul J Marotta MD FRCPC ${ }^{1}$, Ivo W Graziadei MD ${ }^{2}$, Cameron N Ghent MD FRCPC ${ }^{1}$
}

\begin{abstract}
PJ Marotta, IW Graziadei, CN Ghent. Muscle cramps: A 'complication’ of cirrhosis. Can J Gastroenterol 2000;14(Suppl D): 21D-25D. Muscle cramps are a common complaint in clinical practice. They are associated with various metabolic, endocrine, neurological and electrolyte abnormalities. A variety of hypotheses have been generated to explain the cause of muscle cramping, yet none has been able to support a consistent pathophysiological mechanism. Muscle cramps are painful, involuntary contractions of skeletal muscle. They occur frequently in individuals with cirrhosis, regardless of the etiology, and are thought to be a symptom of cirrhotic-stage liver disease.

The pathophysiology of these cramps remains elusive; hence, a specific therapy has not been identified. Many therapeutic approaches have been offered, yet their efficacy, safety and mechanism of action remain poorly defined. This review defines muscle cramps and illuminates its prevalence in the cirrhotic individual. Current theories relating to the pathogenesis of muscle cramps are reviewed, and an overview of the various pharmacological agents that have had therapeutic success for this distressing and frustrating symptom is provided.
\end{abstract}

Key Words: Cirrhosis; Muscle cramps; Vitamin E

\section{Les crampes musculaires comme complications de la cirrhose}

RÉSUMÉ : Dans la pratique clinique, les patients sont nombreux à se plaindre de crampes musculaires. Ces dernières sont associées à diverses anomalies métaboliques, endocriniennes, neurologiques et électrolytiques. Plusieurs hypothèses ont été avancées pour expliquer les causes des crampes musculaires. Or, personne n'a encore pu en confirmer le mécanisme pathophysiologique. Les crampes musculaires sont des contractions involontaires et douloureuses des muscles squelettiques. Elles affectent souvent les sujets cirrhotiques, peu importe l'étiologie de la cirrhose, et seraient un symptôme de maladie hépatique au stade de la cirrhose.

La pathophysiologie de ces crampes reste à élucider. Aucun traitement spécifique n'a donc encore pu être établi. De nombreuses approches thérapeutiques ont été proposées, mais leur efficacité, leur innocuité et leur mode d'action sont encore relativement imprécis. Cette synthèse définit les crampes musculaires et met au jour sa prévalence chez l'individu cirrhotique. Les théories actuelles à propos de la pathogenèse des crampes musculaires sont passées en revue et on fait le bilan des divers agents pharmacologiques qui ont permis de traiter avec succès ce symptôme frustrant et ennuyeux.

\section{DEFINITION}

The general term 'cramp' has been used to define a variety of muscle symptoms that involve pain or contraction of a single muscle or muscle group. According to the American Association of Electrodiagnostic Medicine Glossary of Terms (1), this broad definition of 'cramp' also encompasses a confusing array of additional terms such as 'spasm', 'myalgia' and 'contracture'. A more precise definition for 'muscle cramp' is required. A working definition was established to help refine the physiological, electromyographic and clinical characteristics of muscle cramps $(2,3)$.

A 'true muscle cramp' is characterized clinically as an involuntary, painful, visible or palpable muscle contraction. The onset is abrupt, generally occurring at rest, and often is nocturnal. The pain is intense yet brief. The pain and the contraction resolve spontaneously in seconds to several minutes. The calf is the area most commonly affected, but cramps in the fingers and hands occur in $30 \%$ of patients $(4,5)$.

True muscle cramps are painful and electromyographically exhibit an increased frequency of motor unit action potentials that spread throughout the muscle group and produce a sustained muscle contraction. This feature helps to differentiate various muscle conditions because involuntary muscle contractions are not observed in disorders such as myositis or myalgia, and pain is not a feature of myotonia (6) (Table 1). A muscle 'contracture' is also involuntary; however, it is electrically silent (7). Involuntary muscle con-

\footnotetext{
${ }^{1}$ Liver Unit, University of Western Ontario, London, Ontario; ${ }^{2}$ Division of Gastroenterology, University of Innsbruck, Innsbruck, Austria Correspondence and reprints: Dr Paul J Marotta, Medical Director, Liver Transplantation, University Campus, London Health Sciences Centre,

339 Windermere Road, London, Ontario N6A 5A5. Telephone 519-663-3406, fax 519-663-3858, e-mail Paul.Marotta@lhsc.on.ca Received for publication October 7, 1998. Accepted April 26, 1999
} 
TABLE 1

Definitions of muscle cramps and cramp-like phenomena

\begin{tabular}{lc}
\hline Term & \multicolumn{1}{c}{ Definition } \\
\hline True muscle cramps & $\begin{array}{c}\text { An involuntary, painful muscle contraction } \\
\text { associated with an increased frequency of } \\
\text { motor unit action potentials } \\
\text { Muscle contracture }\end{array}$ \\
$\begin{array}{c}\text { An involuntary state of sustained muscle } \\
\text { contraction that has no associated action } \\
\text { potentials (electrically silent), and the } \\
\text { inability of the muscle fibres to undergo } \\
\text { relaxation } \\
\text { Dystonia }\end{array}$ \\
$\begin{array}{c}\text { Simultaneous contraction of both agonist and } \\
\text { antagonist muscle groups } \\
\text { A syndrome of sensory and motor neuron } \\
\text { hyperexcitability, with resultant motor } \\
\text { hyperactivity (muscle spasms) and sensory } \\
\text { hyperactivity (paresthesia) }\end{array}$ \\
\hline
\end{tabular}

tractions occur in dystonia, where contraction of agonist and antagonist muscle groups result in body contortions, and in tetany, where the generalized nerve hyperexcitability produces both diffuse motor activity and sensory disturbances (paresthesia).

The focus herein is on true muscle cramps and not on other cramp-like phenomena.

\section{PREVALENCE}

Many benign and pathological conditions are associated with muscle cramps (Table 2). Regardless of the cause, the clinical and electromyographic characteristics are identical, strongly suggesting a common pathophysiology (8-10).

The prevalence of benign muscle cramps has been difficult to determine. Lack of a consistent definition, subjectiveness of the symptom and selection bias taint the few studies that have been performed. A questionnaire study from the Netherlands found that $8 \%$ of an unselected adult population reported at least weekly muscle cramps (11). Objective studies using electromyography revealed that symptomatic muscle cramps are present in as much as $16 \%$ of the general population (12).

Through careful observation, it was recognized that patients with chronic liver disease suffered from these same muscle cramps. The uniformity of these complaints prompted further investigation to establish the prevalence of cramping in this patient population. Konikoff and Theodor (13) were the first to report that $88 \%$ in a series of 33 patients with cirrhosis had painful muscle cramps. The symptoms occurred several times per week in more than half of the patients (13). Chao et al (14) reported a prevalence of muscle cramps of $64 \%$ in a cohort of Chinese patients with established cirrhosis. A controlled study by Kobayashi et al (15) revealed that $31 \%$ of 80 cirrhotic Japanese patients had muscle cramps at least once per week. This prevalence was significantly greater than the prevalence in two control groups - one age- and sex-matched healthy group, and one group with chronic noncirrhotic liver disease; muscle cramps occurred in $7 \%$ and $5 \%$ of these patients, respectively.
TABLE 2

Conditions associated with true muscle cramps

Benign conditions
Benign nocturnal muscle cramps in elderly people
Exercise-induced muscle cramps
Pregnancy-related muscle cramps
Neurological conditions
Motor neuron disease, eg, amyotrophic lateral sclerosis
Radiculopathy, eg, spinal stenosis
Peripheral neuropathy
Miscellaneous conditions
Hemodialysis
Volume depletion
Cirrhosis
Parenteral nutrition
Adrenal deficiency
Malignancy
Uremia
Hyponatremia
Drugs (diuretics, morphine, beta-blockers, verapamil)

The prevalence of muscle cramps in patients with underlying cirrhosis in the United States had not been determined until recently. Abrams et al (16) compared the reports of painful muscle cramps in patients with cirrhosis with that of two other control groups - patients with chronic liver disease without cirrhosis and patients with congestive heart failure managed with diuretics. The latter group was included because diuretics have been implicated as a cause of muscle cramps (6). In addition, the use of beta-blockers has been associated with muscle cramps; hence, patients requiring these agents were excluded from the study. In this questionnaire study, $52 \%$ of patients with cirrhosis described painful muscle cramps, in contrast to $7.5 \%$ and $20 \%$ of patients in the respective control groups. Only 50\% of those with cirrhosis were maintained on constant diuretics compared with $90 \%$ of the heart failure group, suggesting that the use of diuretics was not the primary cause of the muscle cramps. Furthermore, weekly cramps were reported in $22 \%$ of those with cirrhosis and in only $5 \%$ of those in the control groups $(\mathrm{P}<0.02)$.

Chronic, painful muscle cramps are a common symptom in patients with cirrhosis. The prevalence ranges from $22 \%$ to $88 \%$, reflecting the lack of uniform diagnostic criteria. Clinically relevant muscle cramps should be defined by their frequency and severity, and hence should occur at least once per week, affect the patient's quality of life and require analgesia. These features occur in $12 \%$ to $42 \%$ of patients with cirrhosis (15-17). The higher prevalence seen in patients with cirrhosis compared with those without cirrhosis suggests that cirrhosis itself is involved in the pathogenesis.

\section{PATHOPHYSIOLOGY}

The pathophysiology of muscle cramps is poorly understood (18). The leading theory is that they have a neural origin. Muscle cramps can be experimentally induced by repetitive 
electrical stimulation of peripheral nerves $(19,20)$. Cramps also persist during spinal anesthesia and in areas distal to transected nerves (5). These data, coupled with the clinical relation of muscle cramps and lower motor neuron diseases (eg, amyotrophic lateral sclerosis, radiculopathies), suggest that the neural origin is localized to the peripheral nervous system (4).

The precise abnormality in the peripheral nervous system is unknown. Neurophysiological studies have shown that high frequency bursts of action potentials arise from abnormally excitable terminal motor nerve fibres that spontaneously propagate the impulses to other muscle groups, leading to the clinical manifestation of muscle cramps (6). These intramuscular motor nerve terminals are unmyelinated and possess physiological properties different from those of extramuscular nerve fibres. The hyperexcitability of these motor nerve terminals may be related to an abnormal sensitivity to neurochemical transmitters or to the local electrochemical environment. The varied causes of muscle cramps (dehydration, diuretics, diarrhea, hemodialysis) have in common the potential to alter the intramuscular extracellular electrochemical environment $(21,22)$.

\section{TREATMENT}

Treatment of muscle cramps remains rather empirical. Quinine sulphate is the most widely used agent, yet many other treatments have had anecdotal success, including fluoride (23), vitamin B12 (24), vitamin E (25), taurine (26), riboflavin (27), verapamil (28), calcium (29), tocainide (30), hydroquinine (31) and transcutaneous nerve stimulation (32).

Quinine sulphate: Quinine sulphate and related derivatives are the most commonly prescribed agents in the United States for the treatment of muscle cramps (33). The pharmacological basis of these agents stems from their ability to increase the refractory period of skeletal muscle cells and to decrease the excitability of the motor nerve terminals (34). Quinine and its derivatives undergo both renal and hepatic metabolism. Indeed, it is suggested that these agents be used with extreme caution in the presence of hepatic and/or renal insufficiency because of the potential for toxic accumulation of active metabolites. Although there is sound pharmacological grounds for the use of these agents, evidence of therapeutic efficacy is poor and is based on uncontrolled studies conducted in the 1930s and 1940s. Recent randomized, controlled clinical trials have been performed, but have been limited by small sample size and the subjectiveness of the outcome measure. Five randomized, controlled trials have addressed the use of quinine for muscle cramps, and the results have been mixed (35-39). The discrepancy in efficacy may be related to differences in patient populations, concomitant use of diuretics and varied dosages of quinine. The positive studies comprised a combined total of 26 patients. Based on these limited data, quinine remains the most prescribed agent for the treatment of muscle cramps regardless of the cause (40).

Therapeutic trials in patients with cirrhosis and muscle cramps had not been performed until 1991, at which time
Lee et al (41) completed a randomized study using quinidine sulphate, a dextroisomer of quinine, in the treatment of 31 patients with cirrhosis. Patients were enrolled if they reported having had at least two muscle cramps per week for at least one year. Quinidine sulphate was given orally for four weeks (200 mg twice daily). The serum quinidine level was followed and was kept at a level considered subtherapeutic for antiarrhythmic use. There was an impressive benefit $88 \%$ of patients in the treatment arm and $13 \%$ in the placebo group showed a greater than $50 \%$ reduction in the number of reported muscle cramps during the trial period. The decrease in muscle cramps was inversely proportional to the serum quinidine level, and apart from mild diarrhea seen in five patients (31\%), quinidine was well tolerated. Based on these results, serum levels of quinidine that are below the recommended therapeutic range for antiarrhythmic action are thought to be effective therapy for muscle cramps in patients with cirrhosis. Higher serum quinidine levels (not observed in this trial) can lead to adverse effects, including nausea, vomiting, tinnitus, headache, rash and hypersensitivity reactions. Serious toxicity, including visual disturbance (42), permanent blindness $(43,44)$, agranulocytosis (45), immune thrombocytopenia (46), renal insufficiency, prolongation of the QT interval, cardiac arrhythmia and sudden cardiac death can occur and must be recognized. It is recommended that serum quinidine levels be monitored and routine electrocardiograms be performed as monitoring procedures during therapy with this agent.

Taurine: Taurine is an amino acid that has been shown to reduce skeletal muscle hyperexcitability (26). Intramuscular taurine levels are depleted in cirrhosis, leading to motor nerve terminal hyperexcitability and subsequent muscle cramps (47). It has been shown to be effective for the treatment of muscle cramps in patients with cirrhosis (48); in this study, taurine given orally, $6 \mathrm{~g}$ daily for six months resulted in the complete resolution of muscle cramps in $66 \%$ of $12 \mathrm{pa}-$ tients with cirrhosis of the liver. This pilot study depicted a safe and seemingly effective therapeutic strategy. Larger, controlled trials are required.

Eperisone hydrochloride: Eperisone hydrochloride, an antispastic agent, was used in the treatment of 18 patients with cirrhosis; 11 (61\%) patients treated with 150 to $300 \mathrm{mg} /$ day for eight weeks reported complete resolution of muscle cramps, and the remainder experienced a reduction in the frequency of muscle cramps (15). Treatment was discontinued in three $(17 \%)$ patients - in one because of unrelated issues and in the other two because of adverse gastrointestinal complaints.

Tocopherol (vitamin E): Traber et al (49) described that low tocopherol levels in nervous tissue could produce peripheral neuropathy. Thus, vitamin E deficiency may have a role in the pathogenesis of muscle cramps $(50,51)$. Anecdotal reports of improvement in the symptoms of benign, nocturnal leg cramps using oral tocopherol (vitamin E) have led to further evaluation of this agent in individuals with cirrhosis (25). Konikoff et al (17) treated 13 patients with cirrhosis and painful muscle cramps with vitamin E (tocopherol ace- 
TABLE 3

Agents used for the treatment of muscle cramps in patients with cirrhosis of the liver

\begin{tabular}{|c|c|c|c|c|}
\hline Agent & Reference & Study type & Dosing & Effect \\
\hline Quinidine sulphate & 41 & $\begin{array}{l}31 \text { cirrhotics; randomized, } \\
\text { single-blind }\end{array}$ & $\begin{array}{l}200 \text { mg orally bid for four } \\
\text { weeks }\end{array}$ & Symptoms reduced in $88 \%$ \\
\hline Taurine & 48 & $\begin{array}{l}12 \text { cirrhotics; uncontrolled, } \\
\text { open-label }\end{array}$ & $\begin{array}{l}6 \text { g orally daily for } \\
\text { six months }\end{array}$ & Symptoms resolved in 66\% \\
\hline Eperosine hydrochloride & 15 & $\begin{array}{l}18 \text { cirrhotics; uncontrolled, } \\
\text { open-label }\end{array}$ & $\begin{array}{l}150 \text { to } 300 \text { mg orally daily for } \\
\text { eight weeks }\end{array}$ & Symptoms resolved in 61\% \\
\hline Tocopherol acetate (vitamin E) & 17 & $\begin{array}{l}13 \text { cirrhotics; uncontrolled, } \\
\text { open-label }\end{array}$ & $\begin{array}{l}200 \text { mg orally tid for four } \\
\text { weeks }\end{array}$ & Symptoms reduced in $100 \%$ \\
\hline Human albumin & 52 & 12 cirrhotics; single-blind & $\begin{array}{c}100 \mathrm{~mL} \text { of } 25 \% \text { intravenously, } \\
\text { weekly for four weeks }\end{array}$ & Symptoms reduced in 83\% \\
\hline
\end{tabular}

tate) $200 \mathrm{mg}$ three times daily for four weeks. There was significant improvement in the level of pain, and in the frequency and duration of the muscle cramps in all patients, without any adverse effects.

Human albumin: Angeli et al (52) suggested that the reduced effective circulating plasma volume seen in cirrhosis contributes to the pathogenesis of muscle cramps. A therapeutic trial in which intravenous placebo was administered weekly for four weeks, followed by intravenous human albu$\min (100 \mathrm{~mL}$ of $25 \%$ human albumin) weekly for four weeks was performed in 12 patients with cirrhosis. No significant change was reported in the frequency of muscle cramps during the placebo phase, whereas a significant reduction occurred during the albumin infusion phase. Unfortunately, the improvement was transient - noticeable only during the treatment phase.

\section{SUMMARY}

True muscle cramps are characterized by involuntary, painful contractions. The prevalence of such cramping in cirrhotic patients varies from $22 \%$ to $88 \%$. Clinically significant muscle cramps - those that occur with great frequency, affect the individual's quality of life or require significant analgesia - occur less frequently ( $8 \%$ to $20 \%$ ).

The pathogenesis of muscle cramps remains unknown but involves the peripheral nervous system, specifically at the level of the intramuscular motor nerve terminals. The hyperexcitability of these unmyelinated fibres is likely due to an abnormal sensitivity to the local extracellular environment. Disturbance to local constituents (electrolytes, minerals, water composition, vitamin levels) occurs in many conditions that feature muscle cramps (ie, dehydration, hemodialysis, diuretic use and cirrhosis).

A single pharmacological agent that displays unequivocal benefit has yet to evolve (Table 3). Quinine and its derivatives are the most common agents prescribed for this condition, yet adequate clinical trials have yet to be performed to support this practice fully. Although, anecdotally, these agents are efficacious, further studies are required. The continued use of these derivatives is acceptable, yet their potential toxicities must be appreciated.

Oral taurine exhibits a treatment benefit and has minimal toxicity; this agent requires further evaluation. The use of vitamin $E$ is perhaps the most interesting development in the therapy of muscle cramps in patients with cirrhosis. This agent has virtually no toxicity and, hence, is the logical choice for further clinical evaluation. Human albumin infusion improves symptoms yet is invasive, transient and expensive.

True muscle cramps should be considered a complication, a symptom or an extrahepatic manifestation of cirrhosis. They occur commonly and can adversely affect an individual's quality of life. Patients with cirrhosis should be questioned specifically for the presence, frequency and severity of muscle cramps. The efficacy and safety of agents such as vitamin $\mathrm{E}$ and taurine must be further evaluated before their widespread use is recommended, yet these agents hold sufficient promise. Therapies that are invasive or costly cannot be justified for this troubling but not life-threatening symptom.

\section{REFERENCES}

1. AAEM Glossary of Terms in Clinical Electromyography. Muscle Nerve 1987;10(8 Suppl):G1-60.

2. McGee SR. Muscle cramps. Arch Intern Med 1990;150:511-8.

3. Simchak AC, Pascuzzi RM. Muscle cramps. Semin Neurol 1991;11:281-7.

4. Layzer RB. Diagnostic implications of clinical fasciculations and cramps. In: Rowland LP, ed. Human Motor Neuron Diseases. New York: Raven Press, 1980:23-7.

5. Layzer RB. Motor unit hyperactivity states. In: Vinken PJ, Bruyn GW, eds. Handbook of Clinical Neurology. Amsterdam: North Holland, 1980:295-316.

6. Joekes AM. Cramp: A review. J R Soc Med 1982;75:546-9.

7. Kirchberger MA, Schwartz IL. Excitation and contraction of skeletal muscle. In: West J, ed. Physiological Basis of Medical Practice. Baltimore: Williams \& Williams,1985:58-106.

8. Steiner I, Siegal T. Muscle cramps in cancer patients. Cancer 1989;6:574-7.

9. Layzer RB. Muscle pain, cramps, and fatigue. In: Engel AG, ed. Myology. New York: McGraw Hill, 1986;66:1907-22.

10. Layzer RB. Endocrine disorders. In: Layzer RB, ed. Neurologic Manifestations of Systemic Disease. Philadelphia: FA Davis, 1985:234-66.

11. Jansen PHP, Joosten EMG, Van Dijck JAAM, et al. The incidence of muscle cramp. J Neurol Neurosurg Psychiatry 1991;54:1124-5.

12. Norris FH, Gasteiger EL, Chatfield PO. An electromyographic study of induced and spontaneous muscle cramps. EEG Clin Neurophysiol 1957;9:139-47.

13. Konikoff F, Theodor E. Painful muscle cramps. A symptom of liver cirrhosis? J Clin Gastroenterol 1986;8:669-72. 
14. Chao Y, Lee FY, Tsai YT, et al. Muscle cramps in liver cirrhosis. Chin J Gastroenterol 1989;6:163-9.

15. Kobayashi Y, Kawasaki T, Yoshimi T, et al. Muscle cramps in chronic liver diseases and treatment with antispastic agent. Dig Dis Sci 1992;37:1145-6.

16. Abrams GA, Concato J, Fallon MB. Muscle cramps in patients with cirrhosis. Am J Gastroenterol 1996;91:1363-6.

17. Konikoff F, Ben-Amitay G, Halpern Z, et al. Vitamin E and cirrhotic muscle cramps. Isr J Med Sci 1991;27:221-3.

18. Jansen PHP, Joosten EMG, Vingerhoets HM. Muscle cramp: main theories as to aetiology. Arch Psychiatry Neurol Sci 1990;239:337-42.

19. Lambert EH. Electromyography in amyotrophic lateral sclerosis. In: Norris FN Jr, Kurland LT, eds. Motor Neuron Diseases: Research on Amyotrophic Lateral Sclerosis and Related Disorders. New York: Grune \& Stratton, 1985:135-53.

20. Lanari A, Muchnik S, Rey N. Muscular cramp mechanism. Medicina 1973;33:235-40.

21. Hall AJ. Cramp and salt balance in ordinary life. Lancet 1947;ii:231-3.

22. Layzer RB. Renal disorders. In: Layzer RB, ed. Neuromuscular Manifestations of Systemic Disease. Philadelphia: Davis, 1985:293-4.

23. Knowles FW. Fluoride and leg cramps. NZ Med J 1981;93:60-3.

24. Aitchison WR. Nocturnal cramps. NZ Med J 1974;80:137-9.

25. Ayres S, Mihan R. Nocturnal leg cramps: a progress report on response to vitamin E. South Med J 1974;67:1308-12.

26. Durelli L, Mutani R, Fassio F, et al. Taurine and hyperexcitable human muscle: Effects of taurine on potassium-induced hyperexcitability of dystrophic myotonic and normal muscles. Ann Neurol 1982;11:258-65.

27. Morgan AA. Treatment of cramp. J R Soc Med 1983;76:712-3.

28. Farber HI. Verapamil vs quinine in recumbent nocturnal leg cramps in the elderly. Arch Intern Med 1990;150:920-1.

29. Hammar M, Larsson L, Tegler L. Calcium treatment of leg cramps in pregnancy. Acta Obstet Gynecol Scand 1981;60:345-7.

30. Puniani TS, Bertorini TE. Tocainide therapy in muscle cramps and spasms due to neuromuscular disease. Muscle Nerve 1991;14:280-5.

31. Jansen PHP, Veenhuizen KCW, Verbeek ALM, et al. Efficacy of hydroquinine in preventing frequent ordinary muscle cramp outlasts actual administration. J Neurol Sci 1994;122:157-61.

32. Reid HE. Footnote to cramp. Lancet 1972;ii:1312-3.

33. Sidorov J. Quinine sulfate for leg cramps: does it work? J Am Geriatr Soc 1993;41:498-500.

34. Gootnick A. Night cramps and quinine. Arch Intern Med 1943;71:555-62.
35. Lim SH. Randomized double-blind trial of quinine sulfate for nocturnal leg cramp. Br J Clin Pract 1986;40:462-6.

36. Fung MC, Holbrook JH. Placebo-controlled trial of quinine therapy for nocturnal leg cramps. West J Med 1989;151:42-4.

37. Jones K, Castleden CM. A double-blind comparison of quinine for relief of night cramps. Age Ageing 1983;12:155-8.

38. Warburton A, Royston JP, O'Neill CJA, et al. A quinine a day keeps the leg cramps away. Br J Clin Pharmacol 1987;23:459-65.

39. Management of muscle cramps. Drug Ther Bull 1982;20:97-8.

40. Quinine for night cramps. Med Lett Drug Ther 1986;28:110-1.

41. Lee FY, Lee SD, Tsai YT, et al. A randomized controlled trial of quinidine in the treatment of cirrhotic patients with muscle cramps. J Hepatol 1991;12:236-40.

42. Bateman DN, Blain PG, Woodhouse KW, et al. Pharmacokinetics and clinical toxicity of quinine overdosage: lack of efficacy of techniques intended to enhance elimination. Q J Med 1985;214:125-31.

43. Smilkstein MJ, Kulig KW, Rumack BH. Acute toxic blindness: unrecognized quinine poisoning. Ann Emerg Med 1987;16:137-40.

44. Dyson EH, Proudfoot AT, Prescott LF, et al. Death and blindness due to overdose of quinine. Br Med J 1985;291:31-3.

45. Siroty RR. Purpura on the rocks: with a twist. JAMA 1976;235:2521-2.

46. Korbitz BC, Eisner E. Cocktail purpura: quinine-dependent thrombocytopenia. Rocky Mt Med J 1973;70:10-3.

47. Gruener R, Bryant $\mathrm{H}$, Markovitz D, et al. Ionic actions of taurine on nerve and muscle membranes: electrophysiologic studies. In: Huxtable R, Barbeau A, eds. Taurine. New York: Raven Press, 1976:225-42.

48. Matsuzaki Y, Tanaka N, Osuga T. Is taurine effective for treatment of painful muscle cramps in liver cirrhosis? Am J Gastroenterol 1993;88:1466-7.

49. Traber MG, Sokol RJ, Ringel, et al. Lack of tocopherol in peripheral nerves of vitamin E-deficient patients with peripheral neuropathy. N Engl J Med 1987;317:262-5.

50. Sokol RJ, Balistreri WF, Hoofnagle JH, et al. Vitamin E deficiency in adults with chronic liver disease. Am J Clin Nutr 1985;41:66-72.

51. Sokol RJ, Heubi JE, Iannaccone S, et al. Mechanism causing vitamin E deficiency during chronic childhood cholestasis. Gastroenterology 1983;85:1172-82.

52. Angeli P, Albino G, Carraro P, et al. Cirrhosis and muscle cramps: evidence of a causal relationship. Hepatology 1996;23:264-73. 


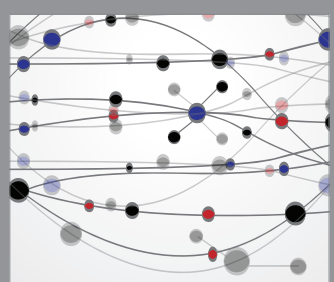

The Scientific World Journal
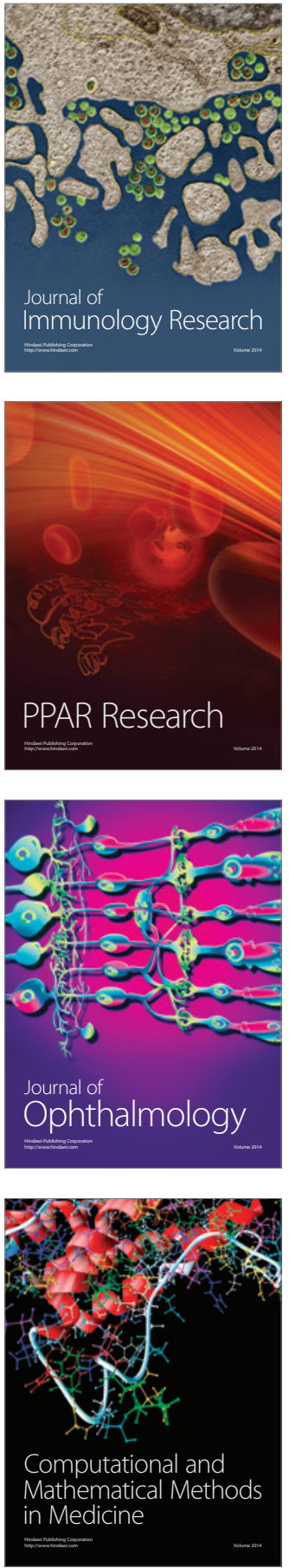

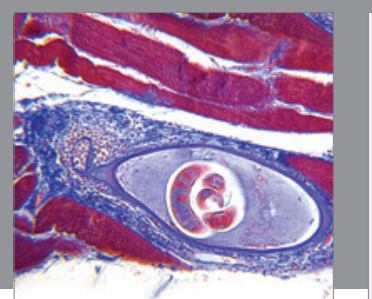

Gastroenterology Research and Practice

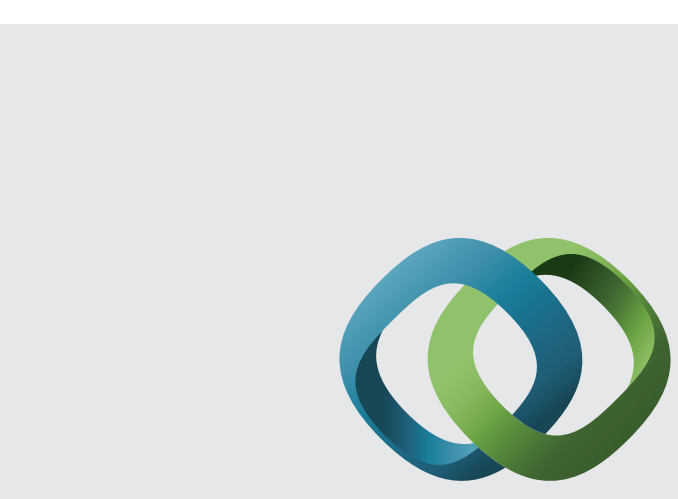

\section{Hindawi}

Submit your manuscripts at

http://www.hindawi.com
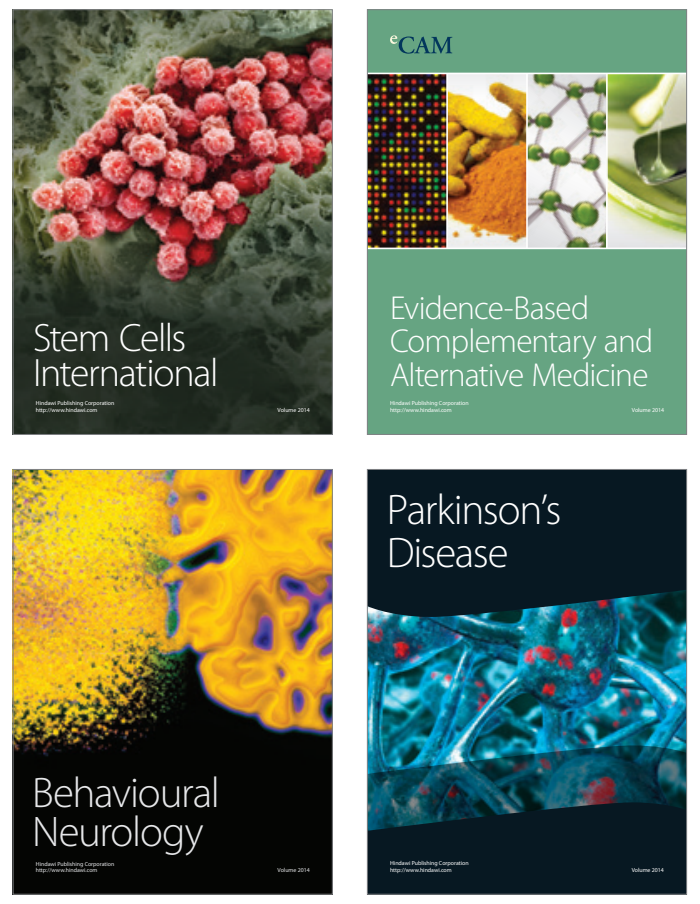
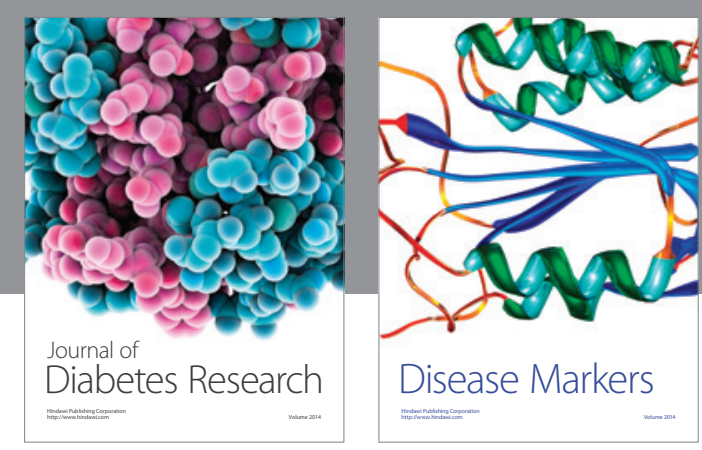

Disease Markers
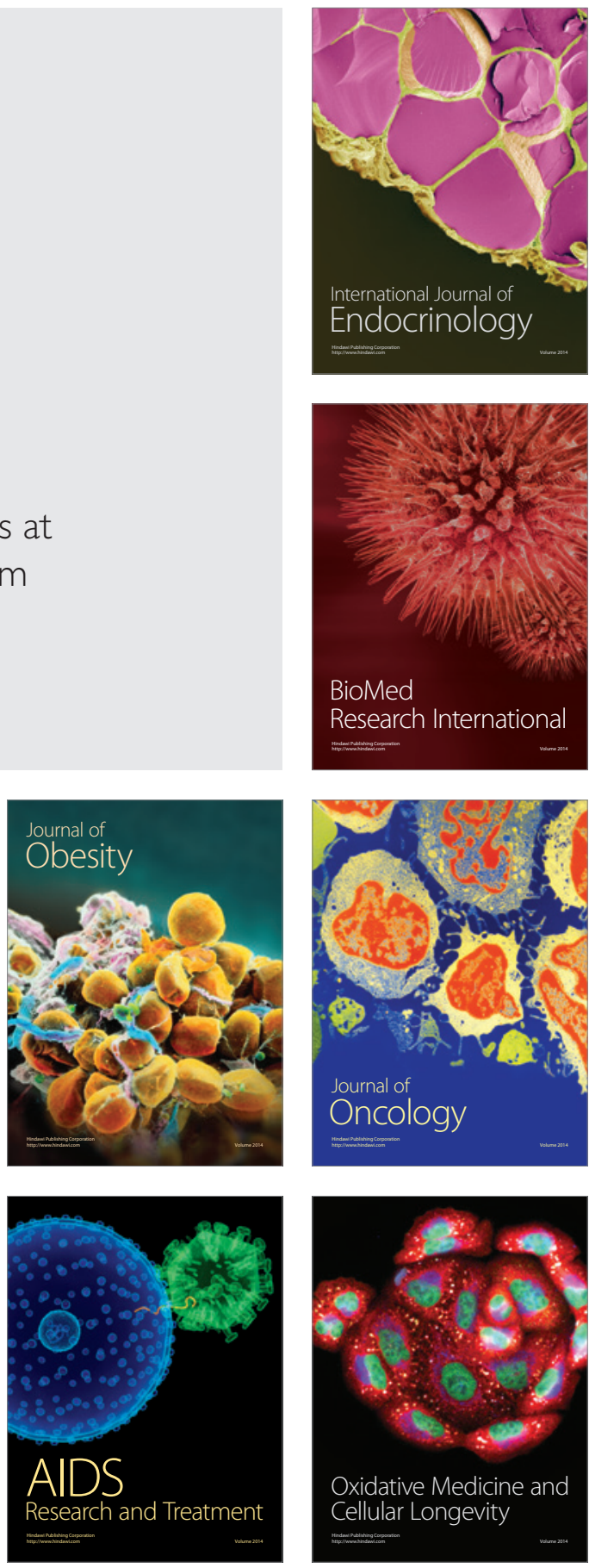